\title{
Caracterização de isolados de Xanthomonas sp. associados a sementes de arroz e diferenciação de estirpes de Xanthomonas oryzae
}

\author{
Isolates characterization of Xanthomonas sp. Associated with rice \\ seed and differentiation of Xanthomonas oryzae strains
}

\author{
Ismail Teodoro de Souza Júnior ${ }^{I^{*}}$ Mauren de Oliveira Santos ${ }^{\mathrm{I}}$ \\ Andréia Mara Rotta de Oliveira ${ }^{I I}$ Marcelo Gravina de Moraes ${ }^{I}$ Valmir Duarte $^{I}$
}

RESUMO

Xanthomonas oryzae pv. oryzae (Xoo) e X. oryzae pv. oryzicola (Xoc), são os agentes causais do crestamento bacteriano da folha (CBF) e da estria bacteriana da folha (EBF), respectivamente, são pragas transmitidas por sementes e sofrem restrição no comércio internacional de arroz, por estarem ausentes em muitos países e possuírem potencial de comprometer seriamente a produção de arroz. Vinte e um isolados oriundos de sementes de arroz do Uruguai e Argentina, Gram negativos, oxidase positiva, com pigmentação amarela típica do gênero Xanthomonas e positivos no ELISA para Xoo, foram caracterizados para determinar a associação destes, com $\boldsymbol{X}$. oryzae e seus patovares. Os isolados foram caracterizados por métodos bioquímicos, biológicos e quanto à sensibilidade a antibióticos. Análises de PCR e qPCR foram realizadas para a confirmação do gênero Xanthomonas e identificação de Xoo e Xoc. A caracterização de 21 isolados de Xanthomonas sp., positivos no ELISA para Xoo, mostrou variabilidade entre os isolados e distinção de Xo.

Palavras-chave: defesa fitossanitária, falso-positivos, métodos moleculares, Oryza sativa.

\section{ABSTRACT}

Xanthomonas oryzae pv. oryzae (Xoo) and $X$. oryzae pv. oryzicola (Xoc), causal agents of bacterial leaf blight (BLB) and bacterial leaf streak (BLS), respectively, are pests transmitted by seeds and suffer restriction on international rice trade, because are absent in many countries and have potential to compromise seriously rice production. Twenty-one isolates from rice seeds from Uruguay and Argentina, Gram negative, oxidase positive, with typical yellow pigmentation of genus Xanthomonas and positive in ELISA for Xoo, were characterized to determine their association with $\boldsymbol{X}$. oryze pathovars. Isolates were characterized by biochemical, biological and antibiogram methods. PCR and qPCR analyzes were performed to confirm genus Xanthomonas and identification of Xoo and Xoc. Characterization of 21
Xanthomonas sp. isolates positive on ELISA to Xoo, showed variability among isolates and distinction of Xo.

Key words: phytosanitary security, false-postive, molecular methods, Oryza sativa.

\section{INTRODUÇÃO}

$\mathrm{O}$ crestamento bacteriano foliar (CBF) e a estria bacteriana da folha (EBF) do arroz são doenças causadas pelas bactérias Xanthomonas oryzae pv. oryzae (Xoo) e $X$. oryzae pv. oryzicola (Xoc), respectivamente. São doenças endêmicas, na maioria dos países da Ásia e parte da África Ocidental, e o aparecimento dos sintomas em qualquer fase de desenvolvimento da planta é favorecido por temperaturas acima de $28^{\circ} \mathrm{C}$ e alta umidade, em países de clima tropical e subtropical, principalmente em sistemas de cultivo irrigado (GOTO, 1992). O CFB é uma das mais graves doenças do arroz, causando perdas que variam de 20 a $30 \%$ da produção, podendo chegar a $75 \%$ quando as condições são favoráveis à doença (OU, 1985). As perdas de rendimento devido a EBF costumam variar de 1,5 a $20 \%$, no entanto, sob condições favoráveis para a disseminação, pode causar reduções de até $32 \%$ da produção de grãos (OU, 1985; IRRI 2014).

Essas bactérias são consideradas pragas quarentenárias ausentes (A1) para o Brasil (D.O.U, 2013). O risco da introdução da Xoo no Brasil já foi

\footnotetext{
'Departamento de Fitossanidade, Universidade Federal do Rio Grande do Sul (UFRGS), Av. Bento Gonçalves, 7712, Agronomia, 91540-000, Porto Alegre, RS, Brasil. E-mail: ismail.teodoro@ufrgs.br. *Autor para correspondência.

${ }^{I I}$ Fundação Estadual de Pesquisa Agropecuária (FEPAGRO), Porto Alegre, RS, Brasil. 
estabelecido em estudos de análise de risco de pragas, pois o patógeno tem elevado potencial de adaptação em zonas de clima temperado e tropical do país. Com o aumento do intercâmbio comercial de sementes entre países, tornou-se necessária a implantação de medidas fitossanitárias que minimizem os riscos da entrada de pragas ausentes no país (MARTINS \& OLIVEIRA, 2007).

Dentre os métodos de detecção dessas bactérias, estão incluídas as técnicas sorológicas (ELISA-Enzyme Linked Immunosorbent Assay). No entanto, tais técnicas podem gerar reações cruzadas com bactérias saprófitas presentes em tecidos de plantas ou no solo, levando a resultados falsopositivos, exigindo vários testes complementares para verificação da identidade, semelhança com tais pragas e evitar erros nos testes de detecção em sementes de arroz. Nesse sentido, o presente trabalho teve por objetivo a caracterização de 21 isolados de Xanthomonas sp., positivos para Xoo no ELISA, utilizando métodos bioquímicos, biológicos e moleculares para a diferenciação de Xanthomonas associadas ao arroz, de Xoo e Xoc.

\section{MATERIAL E MÉTODOS}

Neste estudo, foram utilizados 21 isolados bacterianos amarelos, obtidos de sementes de arroz oriundas da Argentina e Uruguai da safra 2009/2010 (Tabela 1). Esses isolados foram submetidos a crescimento em meio BDA (batata dextrose ágar), teste de oxidase e ao método rápido de Ryu, que consiste em verificar a formação de um fio viscoso pendente, resultante de um esfregaço de cada isolado juntamente com uma gota da solução de $\mathrm{KOH}$ a 3\% (SCHAAD et al., 2001). A identificação sorológica dos 21 isolados realizou-se com anticorpos específicos para Xoo (Agdia, BRA 85000), de acordo com instruções do fabricante. Os 21 isolados apresentaram resultado positivo para Xoo no ELISA. Os isolados foram preservados em glicerol $40 \%$ e em nitrogênio líquido.

Os isolados bacterianos foram submetidos ao crescimento em meio semi-seletivo Wakimoto modificado, desenvolvido para detecção dos patovares de Xo (Sacarose-20g; peptona-5g; $\mathrm{Ca}(\mathrm{NO} 3)_{2} \cdot 4 \mathrm{H}_{2} \mathrm{O}-$ $0,5 \mathrm{~g} ; \mathrm{Na}_{2} \mathrm{HPO}_{4}-0,82 \mathrm{~g} ; \mathrm{FeSO}_{4}-0,05 \mathrm{~g}$; ágar- $\left.17 \mathrm{~g}\right)$ e observado, após $48 \mathrm{~h}$, o crescimento das colônias (MEW \& MISTRA, 1994). Os isolados foram

Tabela 1 - Crescimento em meio semi seletivo Wakimoto modificado, teste de Gram $(\mathrm{KOH})$, produção de xantomonadina e produtos da PCR e qPCR de isolados bacterianos amarelos, positivos no ELISA (Agdia, BRA 85000) para Xanthomonas oryzae pv. oryzae.

\begin{tabular}{|c|c|c|c|c|c|c|c|c|}
\hline Isolado & Cultivar & Origem & $\mathrm{Waq}^{1}$ & $\mathrm{Gram}^{2}$ & $\mathrm{Xant}^{3}$ & PCR Xant ${ }^{4}$ & PCR Multiplex ${ }^{5}$ & $\mathrm{qPCR}^{6}$ \\
\hline 1 - EL5001 & Desconhecida & Uruguai & + & - & + & + & - & - \\
\hline 2 - EL5005 & Desconhecida & Uruguai & + & - & + & + & - & - \\
\hline 3 - EL5007 & Desconhecida & Uruguai & + & - & + & + & - & - \\
\hline 4 - EL5008 & Desconhecida & Uruguai & + & - & + & + & - & - \\
\hline 5 - EL5009 & Desconhecida & Uruguai & + & - & + & - & - & - \\
\hline 6 - EL5010 & Desconhecida & Uruguai & + & - & + & + & - & - \\
\hline 7 - EL5013 & Desconhecida & Uruguai & + & - & + & + & - & - \\
\hline 8 - EL5016 & Desconhecida & Uruguai & + & - & + & + & - & - \\
\hline 9 - EL5019 & Desconhecida & Uruguai & + & - & + & + & - & - \\
\hline 10 - EL6001 & 'Sator’ & Argentina & + & - & + & + & - & - \\
\hline 11 - EL6005 & 'Sator' & Argentina & + & - & + & + & - & - \\
\hline 12 - EL6007 & 'Sator' & Argentina & + & - & + & + & - & - \\
\hline 13 - EL6008 & 'Sator' & Argentina & + & - & + & - & - & - \\
\hline 14 - ЕT3005 & 'Tiba' & Argentina & - & - & + & + & - & - \\
\hline 15 - ЕТ3009 & 'Tiba' & Argentina & + & - & + & + & - & - \\
\hline 16 - ET3017 & 'Tiba' & Argentina & + & - & + & - & - & - \\
\hline 17 - ET4011 & 'Avaxi' & Argentina & + & - & + & + & - & - \\
\hline 18 - ET4012 & 'Avaxi' & Argentina & + & - & + & + & - & - \\
\hline 19 - ET4013 & 'Avaxi' & Argentina & + & - & + & + & - & - \\
\hline 20 - ET3021 & 'Tiba' & Argentina & + & - & + & + & - & - \\
\hline $21-13 \mathrm{I} 10$ & Desconhecida & Argentina & - & - & + & + & - & - \\
\hline
\end{tabular}

${ }^{1}$ Crescimento em meio semi-seletivo Wakimoto modificado para Xo. ${ }^{2}$ Teste de Gram com KOH. ${ }^{3}$ Produção do pigmento xantomonadina. ${ }^{4} \mathrm{PCR}$ com oligonucleotídeos iniciadores universais para Xanthomonas (HAUBEN et al.,1997). ${ }^{5} \mathrm{PCR}$ Multiplex para os patovares de $\boldsymbol{X}$. oryzae (LANG et al., 2010). ${ }^{6} \mathrm{qPCR}$ para Xo com a sonda de hidrólise XRS (ZHAO et al., 2007).

Ciência Rural, v.45, n.12, dez, 2015. 
submetidos à identificação preliminar para o gênero Xanthomonas, seguindo o protocolo para a extração do pigmento xantomonadina (SCHAAD et al., 2001). Foi utilizado, como controle positivo, um isolado de $X$. axonopodis pv. citri.

Após a extração por lise alcalina (DE BOER \& WARD, 1995), o DNA dos 21 isolados bacterianos, com curva típica para o pigmento xantomonadina, foi submetido a amplificações por PCR (Reação da cadeia da polimerase) com os oligonucleotídeos iniciadores 16F27(5'-AGAGTTTGATCMTGGCTCAG-3')e 16R1525(5' - TTCTGCAGTCTAGAAGGAGGTGWTCCAGCC-3') específicos para parte da região do rDNA $16 \mathrm{~S}$ de Xanthomonas spp. (HAUBEN et al., 1997). Foi utilizado, como controle positivo, o DNA (50ng. $\mu \mathrm{l}^{-1}$ ) de um isolado de $\boldsymbol{X}$. axonopodis pv. citri.

Para o teste de sensibilidade a antibióticos pelo método de disco-difusão, uma alíquota de $100 \mu \mathrm{L}$ da suspensão de células bacterianas de cada um dos 21 isolados foi distribuída sobre a superfície do meio de cultura Müeller Hinton em placas de Petri. Em seguida, discos de papel, impregnados com antibiótico, foram colocados, assepticamente, sobre o meio. O ensaio foi realizado utilizandose 11 antibióticos ( $\left.\mu \mathrm{g} \cdot \mathrm{mL}^{-1}\right)$ : clindamicina (2), cloranfenicol (30), eritromicina (15), estreptomicina (10), norfloxacin (10), novobiocina (5), oxacilina (1), rifampicina (5), sulfonamida (300), tetraciclina (30) e vancomicina (30). Foram utilizadas quatro repetições por tratamento. A sensibilidade dos isolados aos antibióticos foi avaliada após $24 \mathrm{~h}$ de incubação a $28^{\circ} \mathrm{C}$, determinando-se o tamanho do halo de inibição. Foi considerado sensível ao antibiótico o isolado que apresentou a formação de um halo de inibição acima de 8mm (WILSON \& POWER, 1989).

Para verificação do uso de diferentes fontes de carbono, foram utilizadas microplacas do Sistema Biolog ${ }^{\circledR}$ (GN Microplate, Biolog), o qual contem 95 fontes. Para isso, foram testados 18 isolados, que primeiramente foram cultivados em meio Biolog Universal Growth Medium (BUGM) e incubados por $24 \mathrm{~h}$ a $28^{\circ} \mathrm{C}$. Após, as colônias bacterianas foram transferidas, com auxílio de um cotonete esterilizado, para solução salina esterilizada e ajustadas visualmente para igualar ao padrão de turbidez do sistema GN Biolog ${ }^{\circledR}$. Alíquotas de $150 \mu \mathrm{L}$ das suspensões de células bacterianas foram dispostas em cada poço das microplacas. A visualização da mudança da cor foi analisada após $24 \mathrm{~h}$ a $28^{\circ} \mathrm{C}$. O perfil de utilização das fontes de carbono de cada isolado foi inserido na base de dados do Sistema Biolog $^{\circledR}$ e posteriormente comparado com as fontes utilizadas por estirpes de $\boldsymbol{X}$. oryzae (VAUTERIN et al., 1995). Os dados foram analisados pelo programa NTSYS-pc versão 2.0 (ROHLF, 1998). A matriz de similaridade foi construída utilizando o coeficiente de simples associação e os agrupamentos feitos de acordo com o método Unweight Group Method with Arithmetic Average (UPGMA).

Para o teste de reação de hipersensibilidade, suspensões de células $\left( \pm 10^{9}\right.$ UFC. $\left.\mathrm{mL}^{-1}\right)$ dos 21 isolados de Xanthomonas sp. foram inoculadas em folhas de tomate (Solanum lycopersicum) e tabaco (Nicotiana tabacum). A suspensão de células bacterianas foi infiltrada no mesófilo com uma seringa hipodérmica com agulha. Foram utilizadas três repetições para cada isolado. A presença de colapso e morte do tecido vegetal foi verificada após 24h (ROMEIRO, 1995). Para o teste de patogenicidade, suspensões de células dos 21 isolados de Xanthomonas sp. foram padronizadas em espectrofotômetro a $\pm 10^{8}$ UFC. $\mathrm{mL}^{-1} \mathrm{e}$ inoculadas em plantas de arroz da cultivar IRGA 410, no estádio fenológico V6-V8, através do corte das folhas com tesoura previamente imersa em suspensão bacteriana (AKHTAR et al., 2008) e também com pequenas picadas de agulhas contendo cultura bacteriana (XIE \& MEW, 1998). Foram utilizadas três repetições para cada um dos métodos. A testemunha constou de plantas inoculadas com água destilada esterilizada. Controles positivos não foram utilizados, devido ao impedimento legal, por serem pragas quarentenárias. Após a inoculação, as plantas foram mantidas em câmara úmida com saco plástico transparente por $48 \mathrm{~h}$. A verificação da presença de sintomas, foi feita 14 dias após a inoculação.

O DNA dos 21 isolados bacterianos foram submetidos a qPCR para detecção de Xo, utilizando os oligonucleotídeos PF: 5'-GAATATCAGCATCGGCAACAG-3' e PR: 5'- TACCGGAGCTGCGCGTT-3' e a sonda de hidrólise P1: FAM-5'CATCGCCTGCTCGGCTACCAGC-3' -MGB (ZHAO et al., 2007). Como controle positivo, foram utilizados $100 \mathrm{ng} . \mu \mathrm{L}^{-1}$ do DNA genômico de Xoc e Xoo. O DNA dos 21 isolados de Xanthomonas sp. foram novamente submetidos a amplificações por PCR multiplex para detecção de Xoo e Xoc com oligonucleotídeos iniciadores para Xo (3756F-CATCGTTAGGACTGCCAGAAG e 3756R-GTGAGAACCACCGCCATCT), Xoo (80F-GCCGCTAGGAATGAGCAAT e 80R-GCGTCCTCGTCTAAGCGATA) e Xoc (3864F-GTGCGTGAAAATGTCGGTTA, 3864 R - G G G AT G G AT G A ATA C G GAT G, $3866 \mathrm{~F}-\mathrm{ATC}$ T C C C A G C AT G T T GATC G, 
3866R-GCGTTCAATCTCCTCCATGT) as

reações ocorreram conforme LANG et al. (2010).

\section{RESULTADOS E DISCUSSÃO}

Os 21 isolados positivos no ELISA para Xoo apresentaram coloração amarela em meio de cultivo BDA, oxidase negativa e foram Gramnegativos no teste de $\mathrm{KOH} \mathrm{3 \%}$. Os isolados ET3005 e 13 I10 não foram capazes de se desenvolver no meio Wakimoto modificado, os demais isolados cresceram normalmente num período de até $48 \mathrm{~h}$ (Tabela 1). Apesar de esse meio ser desenvolvido para o isolamento de Xo, ele não inibe o crescimento de outras Xanthomonas. Assim, este método deve ser utilizado somente para rastrear e não como um método definitivo na deteç̧ão dos patovares de Xo, pois pode permitir a obtenção de resultados falso-positivos. Sabe-se que ambas as bactérias Xoo e Xoc crescem lentamente sobre os meios de isolamento e que bactérias relacionadas à bactériaalvo com o crescimento rápido, podem impedir o desenvolvimento das espécies de interesse, mascarando os resultados (LEE et al., 2009).

Em relação à produção do pigmento xantomonadina, todos os 21 isolados apresentaram curva típica com três picos de absorvância (420, $440,460 \mathrm{~nm}$ ) (Tabela 1). O teste para identificação de xantomonadina é essencial para o início da caracterização de isolados pertencentes ao gênero Xanthomonas, uma vez que, dentre as bactérias, apenas as desse gênero são capazes de produzir esse pigmento (GARRITY et al., 2004).

$\mathrm{Na}$ PCR com oligonucleotídeos iniciadores universais, baseados na região rDNA 16S, observouse que 18 isolados tiveram amplificação do DNA, apresentando um produto de $1518 \mathrm{pb}$, similar ao do controle positivo ( $\boldsymbol{X}$. axonopodis pv. citri). Apenas os isolados EL5009, EL6008 e ET3017 não apresentaram amplificação do fragmento (Tabela 1).

Dentre os antibióticos analisados, rifampicina, tetraciclina e vancomicina inibiram o crescimento de $95 \%$ dos isolados, enquanto cloranfenicol e novobiocina inibiram $90 \%$. Dentre os demais antibióticos, apenas oxalicina não foi capaz de inibir o crescimento de nenhum dos isolados. A variabilidade da sensibilidade aos antibióticos pôde ser observada, sendo que o isolado ET5008 foi sensível a apenas três antibióticos. No entanto, o isolado ET3005 apresentou sensibilidade a 10 antibióticos, sendo resistente apenas contra oxalicina, isso mostra a existência de uma grande variabilidade dentro da população de Xanthomonas saprófitas, para esta característica. Foi formado um grupo de nove isolados e um grupo de dois isolados que apresentaram o mesmo perfil de sensibilidade aos antibióticos. Os demais 10 isolados, apresentaram diferenças entre si quanto à sensibilidade aos antibióticos.

Resultados semelhantes, encontrados por PEREIRA et al. (2003), demonstraram que espécies de Xanthomonas também tiveram os antibióticos cloranfenicol e tetraciclina como os mais efetivos no controle do crescimento bacteriano, mesmo em baixas concentrações. Adicionalmente, o crescimento de Xo foi inibido em meios de cultura suplementados com tetraciclina e oxiciclina na concentração de $0,001 \%$ e com cloranfenicol a $0,005 \%$ (SWINGS et al., 1990). Por outro lado, de acordo com KHAN et al. (2012), o antibiótico cloranfenicol $\left(500 \mu \mathrm{g} \cdot \mathrm{mL}^{-1}\right)$ não inibiu o crescimento de isolados Xoo oriundos do Paquistão. Sendo assim, os antibióticos com maior espectro de ação contra os isolados de Xanthomonas sp. analisados são candidatos a suplementarem meios de cultura seletivos para o isolamento dos patovares de Xo. No entanto, há a necessidade de se obter um antibiograma com diferentes estirpes de Xo, para saber se tais antibióticos podem ser utilizados para elaboração de meios seletivos ou semi-seletivos sem afetar o isolamento de Xo.

Dentre as 95 fontes de carbono que fazem parte do sistema Biolog ${ }^{\circledR}, 12$ delas (sacarose, dextrina, manose, maltose, $\alpha$-D-glicose, celobiose, tween 40 , tween 80 , D-galactose, $\alpha$-D-lactose, lactulose e D-melibiose) destacaram-se por serem metabolizadas por mais de $90 \%$ dos isolados positivos no ELISA. Por outro lado, outras 17 fontes (glicogênio, N-acetilD-galactosamina, adonitol, meso-eritritol, xilitol, ácido p-hidroxifenilacético, ácido itacônico, ácido malônico, ácido sebácico, L-fenilanina, ácido I-piroglutâmico, D-serina, L-treonina, DL-carnitina, feniletilamina, putrescina, 2,3-butanodiol) não foram metabolizadas por nenhum dos isolados. Os perfis metabólicos dos isolados, encontrados na base de dados do sistema Biolog ${ }^{\circledR}$ não permitiram correspondência na identificação dos isolados. VERNIERE et al. (1993), utilizando o sistema Biolog $^{\circledR}$, identificou corretamente em nível de espécie apenas $6,8 \%$ de 148 cepas fitopatogênicas de $\boldsymbol{X}$. axonopodis pv. citri originárias de 24 países. Esse fato se deve, em muitos casos, ao número reduzido de bactérias fitopatogênicas registradas nos bancos de dados do sistema Biolog.

$\mathrm{O}$ uso de fontes de carbono permitiu observar uma ampla variabilidade nos perfis metabólicos dos isolados de Xanthomonas sp. No dendograma construído, baseado no perfil metabólico dos isolados, observou-se a formação de três grupos 
distintos, com uma similaridade acima de 70\% (Figura 1). No entanto, não foi identificada correspondência dos perfis metabólicos dos isolados de acordo com a região de origem e cultivares.

Comparando-se as médias da utilização das fontes de carbono entre os 18 isolados positivos no ELISA, com isolados dos patovares de Xo (VAUTERIN et al., 1995), observou-se que não houve relação para o uso da maioria das fontes de carbono. Apenas as fontes de carbono dextrina e maltose tiveram relação positiva na utilização das fontes de carbono entre os isolados de Xanthomonas com os patovares de Xo. No entanto, quando se compararam as fontes de carbono não utilizadas pelos isolados de Xanthomonas sp., observou-se que 16 das 17 fontes também não foram utilizadas pelos patovares de Xo. $\mathrm{Na}$ descrição de estirpes de Xo por VAUTERIN et al. (1995), D-glicose e D-melibiose não foram usados por nenhuma das estirpes, no entanto, 90\% dos isolados de Xanthomonas sp. associados a sementes de arroz foram capazes de utilizá-las.
Nos resultados dos testes de $\mathrm{RH}$, tanto para plantas de tabaco quanto de tomateiro, não foi observada nenhuma reação de hipersensibilidade incitada pelos 21 isolados positivos no ELISA. Muitos dos isolados de Xanthomonas spp. não induzem RH em plantas de tabaco, mesmo em condições normais de inoculação e incubação (LELLIOTT \& STEAD, 1987). No entanto, foi observado por SHIVALINGAIAH et al. (2012) o aparecimento de necrose nas folhas de plantas de tabaco (Nicotiana tabacum var. xanthii) 24 h após estas serem infiltradas com células de Xoo. Em outro trabalho, JABEEN et al. (2012), testando 123 isolados de Xoo, observaram que 105 destes incitaram RH em plantas de tabaco (Nicotiana rustica). Adicionalmente, plantas de arroz, cultivar IRGA 410, inoculadas com os 21 isolados de Xanthomonas sp., não demonstraram qualquer sintoma após duas semanas.

Os 21 isolados positivos no ELISA para Xoo não apresentaram curva de amplificação na qPCR com a sonda específica para a espécie Xo, apenas o

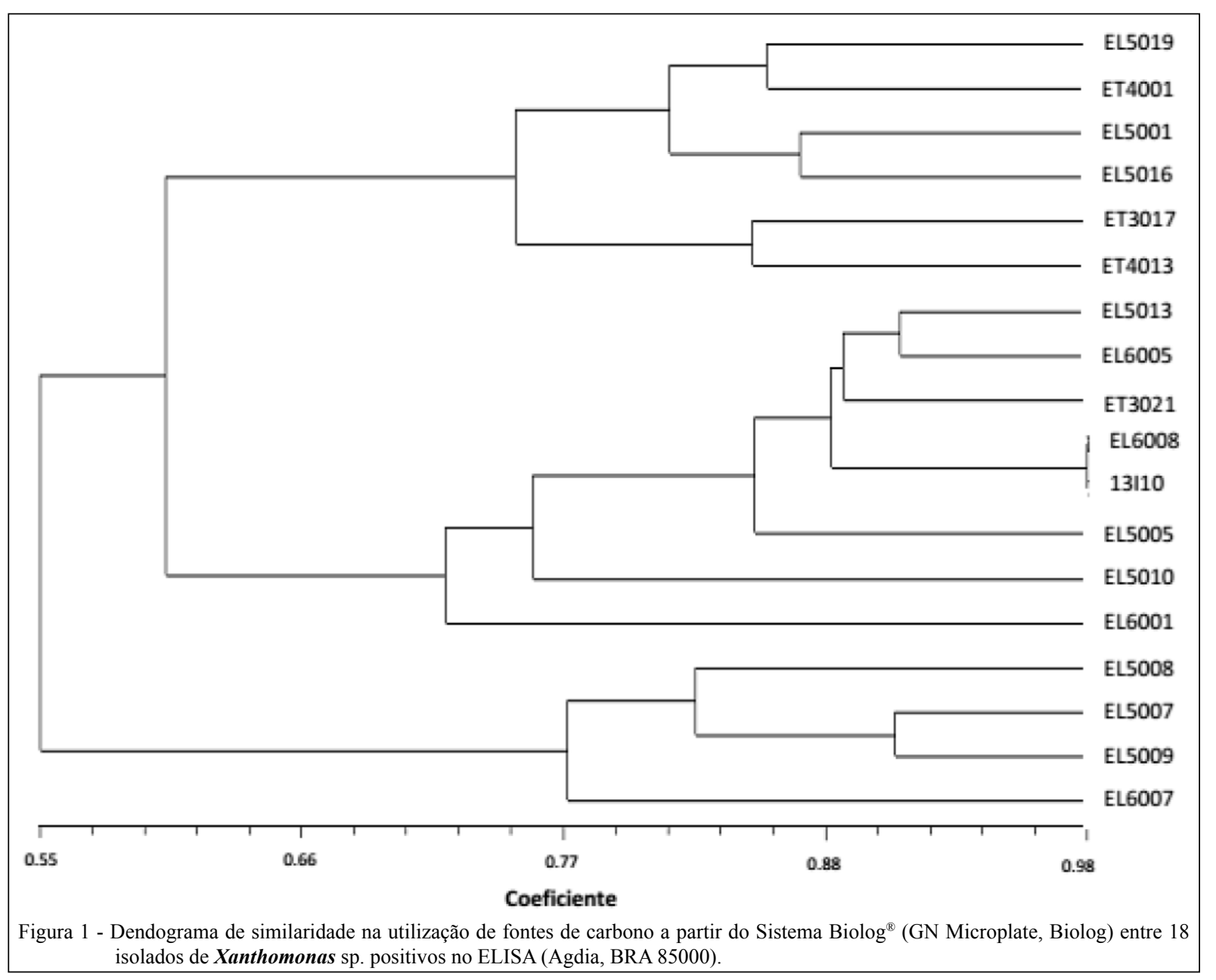

Ciência Rural, v.45, n.12, dez, 2015. 
DNA dos isolados de Xoo e Xoc foram amplificados. $\mathrm{Na}$ PCR multiplex, realizada com oligonucleotídeos específicos para a detecção dos dois patovares de Xo, também não houve amplificação por nenhum dos 21 isolados. Esses mesmos oligonucleotídeos iniciadores mostraram especificidade por amplificar os fragmentos de 164 isolados de Xoo e 89 de Xoc de diferentes regiões (LANG et al., 2010). A possibilidade de os isolados testados serem Xo foi excluída e foi confirmada a existência de reações cruzadas com outras Xanthomonas sp. no ELISA para Xoo.

Com base na interação dos resultados obtidos, verificou-se que as técnicas moleculares, bioquímicas e biológicas utilizadas, permitiram claramente distinguir os 21 isolados de Xanthomonas sp. positivos no ELISA dos patovares de Xo. As técnicas moleculares apresentaram ser mais satisfatórias para diferenciar Xanthomonas saprófitas dos patovares de Xo, visto que os oligonucleotídeos iniciadores específicos para os patovares de Xo e a sonda XRS não amplificaram com nenhum dos 21 isolados. Esses mesmos isolados não foram capazes de incitar reação de hipersensibilidade em plantas de tabaco e tomateiro e nenhum sintoma foi observado em plantas de arroz, independente do método de inoculação utilizado. Além disso, não houve correspondência para a utilização das fontes de carbono entre os isolados de Xanthomonas sp. e os patovares de Xo.

Os resultados obtidos demonstraram que a presença de Xanthomonas sp. não patogênicas, associadas a sementes de arroz, podem gerar resultados falso-positivos no ELISA, que é um método de uso corrente em laboratórios no Brasil, para a detecção de Xo, interferindo no diagnóstico fitossanitário. Os testes bioquímicos indicaram a existência de variabilidade entre os isolados analisados e permitiram diferenciar Xanthomonas sp. de Xo. O conhecimento da diversidade desses isolados oriundos de sementes de arroz é um importante pré-requisito para o desenvolvimento de métodos de detecção, classificação taxonômica e estudos epidemiológicos, principalmente quando há ocorrência de diferentes espécies relacionadas no mesmo hospedeiro, evitando possíveis reações cruzadas com Xo. O destaque ocupado pela cultura do arroz no Brasil e o crescimento da importação de sementes aumenta a necessidade do controle rigoroso por parte da defesa fitossanitária. As condições de clima temperado e tropical do Brasil podem proporcionar ambiente favorável para adaptação dos patovares de Xo. Além disso, o órgão de fiscalização tem interceptado sementes de arroz com essas bactérias, sendo que, nos últimos anos, o Brasil tem importado uma grande quantidade de sementes de arroz da Argentina, Uruguai, EUA e Índia. Embora Xoo e Xoc sejam endêmicas na Índia, os demais países importam sementes de locais onde essas bactérias ocorrem. Esses fatos demonstram a importância da utilização de mais de um método específico que permita a realização das análises fitossanitárias que assegurem a liberação do material vegetal livre desses patógenos, como uma estratégia de manejo em áreas indenes.

\section{CONCLUSÃO}

Isolados de Xanthomonas positivos no ELISA para Xoo apresentam perfis bioquímicos, biológicos e moleculares distintos de $X$. oryzae. Demosntrando que Xanthomonas sp. não patogênicas estão associadas com arroz e interferem no diagnóstico fitossanitário.

\section{REFERÊNCIAS}

AKHTAR, M.A. et al. Comparison of methods of inoculation of Xanthomonas oryzae pv. oryzae in rice cultivars. Pakistan Journal of Botany, v.40, p.2171-2175, 2008. Disponível em: $<$ http://www.pakbs.org/pjbot/PDFs/40(5)/PJB40(5)2171.pdf $>$. Acesso em: 20 jan. 2015.

DE BOER, S.H.; WARD, L. PCR detection of Erwinia carotovora subsp. atroseptica associated with potato tissue. Phytopathology, v.85, p.854-858, 1995. Disponível em: <http://www.bashanfoundation. com/solke/solketissue.pdf >. Acesso em: 22 jan. 2014.

D.O.U (DIÁRIO OFICIAL DA UNIÃO) - Instrução Normativa n.59, de 18 de dezembro de 2013. Estabelece a lista de pragas quarentenárias ausentes e de pragas quarentenárias presentes para o Brasil e aprovar os procedimentos para as suas atualizações. Diário Oficial da União, Poder Executivo, Brasília, DF, 19 dez. 2013.

GARRITY, G.M. et al. Bergey's manual of systematic bacteriology. 2.ed. New York: Springer, 2004. 4001p.

GOTO, M. Fundamentals of Bacterial Plant Pathology. San Diego: Academic Press, 1992. 364p.

HAUBEN, L. et al. Comparison of $16 \mathrm{~s}$ Ribosomal DNA Sequences of All Xanthomonas Species. International Journal of Systematic Bacteriology, v.47, p.328-335, 1997. Disponível em: <http://ijs.sgmjournals.org/content/47/2/328.long $>$. Acesso em: 19 jun. 2014. doi: 10.1099/00207713-47-2-328.

IRRI (INTERNATIONAL RICE RESEARCH INSTITUTE). Bacterial leaf streak. Online. Disponivel em: $<\mathrm{http}: / / \mathrm{www}$. knowledgebank.irri.org/decision-tools/rice-doctor/rice-doctorfact-sheets/item/bacterial-blight $>$. Acesso em: 14 jun. 2014.

JABEEN, R. et al. Isolation, characterization, reservation and pathogenicity test of Xanthomonas oryzae pv. oryzae causing BLB disease in rice. Pakistan Journal of Botany, v.44, p.261265, 2012. Disponível em: <http://www.pakbs.org/pjbot/ PDFs/44(1)/37.pdf>. Acesso em: 21 jan. 2014. 
KHAN J.A. et al. Chemical control of bacterial leaf blight of rice caused by Xanthomonas oryzae pv. oryzae. Pakistan Journal of Phytopathology, v.24, p.97-100, 2012. Disponível em: <http://pjp.pakps.com/files/97-100-Hafiz--Imran-paper.pdf>. Acesso em: 14 jan. 2014.

LANG, J.M. et al. Genomics-based diagnostic marker development for Xanthomonas oryzae pv. oryzae and X. oryzae pv. oryzicola. Plant Disease, v.94, p.311-319, 2010. Disponível em: <http:// apsjournals.apsnet.org/doi/abs/10.1094/PDIS-94-3-0311>. Acesso em: 14 jan. 2014. doi: 10.1094/ PDIS-94-3-0311.

LEE, Y.A et al. Combination of chromogenic differencial medium and estA-especific PCR for isolation and detection of phytopathogenic Xanthomonas spp. Applied and Enviromental Microbiology, v.75, p.6831-6838, 2009. Disponível em: <http:// aem.asm.org/content/75/21/6831>. Acesso em: 12 jan. 2014. doi: 10.1128/AEM.01653-09.

LELLIOTT, R.A.; STEAD, D.E. Methods for the diagnosis of bacterial plant disease. Oxford: Blackwell Scientific Publications, 1987. 216p.

MARTINS, O.M.; OLIVEIRA, M.R.V. Pest risk analysis on the agent of bacterial blight of rice, Xanthomonas oryzae pv. oryzae. In: INTERNATIONAL PLANT PROTECTION CONGRES, 16, 2007, Glasgow. Congress Proceedings... Glasgow: BCPC, 2007. p.566-567.

MEW T.W; MISTRA J.K. A manual of rice seed health testing. Manila: IRRI, Manila (PH), 1994. 122p.

OU, S.H. Rice diseases. Kew, Surrey: Commonwealth Agricultural Bureau. 1985. 380p.

PEREIRA, J.E.S. et al. Identificação e controle com antibióticos de bactérias endofíticas contaminantes em explantes de batata micropropagados. Pesquisa agropecuária brasileira, v.3, p.827-834, 2003. Disponível em: <http://www.scielo.br/pdf/pab/ v38n7/18204.pdf>. Acesso em: 10 jan. 2014. doi: 10.1590/S0100204X2003000700006.

ROHLF, F.J. NTSYS-pc: numerical taxonomy and multivariate analysis system, Version 2.0, User's Guide. New York: Exeter Software. 1998. 37p.

ROMEIRO, R.S. Bactérias fitopatogênicas. Viçosa: UFV, 1995. 283p

SCHAAD, N.W. et al. Laboratory guide for identification of plant pathogenic bacteria. 3.ed. St. Paul. The American Phytopathology Society, 2001. 373p.
SWINGS, J. et al. Reclassification of the causal agents of bacterial blight Xanthomonas campestris pv. oryzae and bacterial leaf streak $\boldsymbol{X}$. campestris pv. oryzicola of rice as pathovars of $\boldsymbol{X}$. oryzae new species Ex Ishiyama 1922 Revived Name. International Journal of Systematic and Evolutionary Microbiology, v.40, p.309-311, 1990. Disponível em: <http://ijsb.sgmjournals. org/content/45/3/472.full.pdf $>$. Acesso em: 09 jan. 2014. doi: 10.1099/00207713-40-3-309.

SHIVALINGAIAH, U.S.; SATEESH, M.K. Detection of Xanthomonas oryzae pv. oryzae in rice seeds by molecular techniques. Asian and Australasian Journal of Plant Science and Biotechnology, v.6, p.44-47, 2012. Disponível em: $<$ https://www. researchgate.net/profile/Mysore Sateesh/publication/230752325 Detection_of_Xanthomonas_oryzae_pv._oryzae_in_Rice_Seeds by_Molecular_Techniques/links/0912f503e11a7c4082000000. pdf $>$. Acesso em: 14 jan. 2014.

VAUTERIN, L. et al. Reclassification of Xanthomonas. International Journal of Systematic Bacteriology, v.45, p.472-489, 1995. Disponível em: <http://ijs.sgmjournals.org/ content/45/3/472.full.pdf + html $>$. Acesso em: 02 jan. 2015. doi: $10.1099 / 00207713-45-3-472$.

VERNIERE, C. et al. Evaluation of the Biolog substrate utilization system to identify andassess metabolic variation among strains of Xanthomonas campestris pv. citri. Applied and Environmental Microbiology, v.59, p.243-249, 1993. Disponível em: <http://aem. asm.org/content/59/1/243.long>. Acesso em: 10 jan. 2014.

WILSON, Z.; POWER, J.B. Elimination of systemic contamination in explants and protoplast cultures of rubber (Hevea brasiliensis Muell. Arg.). Plant Cell Reports, v.7, p.622-625, 1989. Disponível em: $<$ http://link.springer.com/article/10.1007/BF00272044\#page-1>. Acesso em: 15 jan. 2014. doi: 10.1007/BF00272044.

XIE, G.L.; MEW, T.W. A leaf inoculation method for detection of Xanthomonas oryzae pv. oryzicola from rice seed. Plant Disease, v.82, p.1007-1011, 1998. Disponível em: <http://apsjournals. apsnet.org/doi/pdf/10.1094/PDIS.1998.82.9.1007>. Acesso em: 14 jan. 2014. doi: 10.1094/PDIS.1998.82.9.1007.

ZHAO, W.J. et al. Detection of Xanthomonas oryzae pv. oryzae in seeds using a specific TaqMan probe. Molecular Biotechnology, v.35, p.119-127, 2007. Disponível em: <http://link.springer.com/ article/10.1007/BF02686106\#page-1>. Acesso em: 10 jan. 2014. doi: $10.1007 / \mathrm{BF} 02686106$ 